\title{
QUALIDADE E EQUIDADE NA EDUCAÇÃO: UMA VISÃO DESDE AS POLÍTICAS E A GESTÃO EDUCACIONAL
}

\section{CALIDAD Y EQUIDAD EN LA EDUCACIÓN: UNA VISIÓN DESDE LAS POLÍTICAS Y LA GESTIÓN EDUCATIVA}

\author{
QUALITY AND EQUITY IN EDUCATION: A VISION FROM POLICIES AND \\ EDUCATIONAL MANAGEMENT
}

Alexandra Ayach ANACHE
Eladio Sebastián-Heredero

(Orgs.)

As políticas e gestão escolar, hoje mais do que nunca, precisam de uma abordagem global, internacional, interdisciplinar que dê resposta às novas necessidades que são demandadas desde as instituições educativas a todos os níveis do sistema educativo.

Trazemos aqui as palavras de Aranda (2006) quem retoma o informe da Organização para a Cooperação e Desenvolvimento Econômico de 1996 onde já se afirmava que as rápidas mudanças da economia e os avances das tecnologias "poderiam fazer inútil uma formação orientada exclusivamente na direção do profissional, pois a evolução dos conhecimentos e a própria transformação das empresas estava voltando obsoleto o conteúdo que se transmitia nos centros acadêmicos" (p. 1) entendidos no sentido mais amplo, o que evidentemente se torna numa mensagem permanente para navegantes em todos os sentidos.

Isto nos leva a refletir sobre o objeto da educação atual em cada etapa escolar e ao longo da vida e o tipo de cidadãos que estamos formando, com suas competências, nas nossas instituições educativas, as pessoas que nos guiarão num presente não tão remoto. Essa reflexão está conectada com a forma como concebemos as instituições e como é a gestão das mesmas, pois é dentro delas que acontece a educação e segundo esta seja, assim são seus resultados.

A qualidade e a equidade da educação é um aspecto fundamental e multifatorial que é procurado pelos políticos, gestores e educadores de todos os níveis educativos e que vem sendo

\footnotetext{
${ }^{1}$ Universidade Federal de Mato Grosso do Sul (UFMS), Campo Grande - MS - Brasil. Professora no Programa de Pós-Graduação em Educação. Pós-Doutorado em Educação (UNB). ORCID: https://orcid.org/0000-00027937-4448. E-mail: alexandra.anache@gmail.com

${ }^{2}$ Universidad de Alcalá (UAH), Madri - Espanha. Professor Visitante Estrangeiro (UFMS). Doutorado em Educação (UAH) - Espanha. Pós-Doutorado em Educação (UNESP). ORCID: http://orcid.org/0000-0003-02934395. E-mail: eladio.sebastian@gmail.com
}

RPGE- Revista on line de Política e Gestão Educacional, Araraquara, v. 24, n. esp. 2, p. 938-945, set. 2020. e-ISSN:1519-9029 DOI: https://doi.org/10.22633/rpge.v24iesp2.14341 (c) BY-NC-SA 
tratado desde as instituições supranacionais com orientações permanentes e apoio sistemático, assim a UNESCO (2007, p. 7) no informe para América Latina e o Caribe dizia:

En este panorama, la propuesta de educación de calidad para todos a lo largo de la vida enfrenta en la región al menos cuatro desafíos importantes: a) cómo puede hacer una contribución efectiva al crecimiento económico como factor clave que afecta al bienestar de las personas; b) cómo puede contribuir a la reducción de las desigualdades sociales y convertirse en un verdadero canal de movilidad social; c) cómo puede ayudar a combatir la discriminación cultural, la exclusión social, y prevenir la violencia y la corrupción; d) cómo puede contribuir a una mayor cohesión social y al fortalecimiento de los valores democráticos, ampliando las opciones de las personas para vivir con dignidad, valorar la diversidad y respetar los derechos humanos.

São muitos os desafios que nesta declaração de intenções são colocados, algo que nos motivou para fazer esta proposta de Dossiê, com o convite expresso a pesquisadores de reconhecido prestigio da região ibero-americana, com o desafio de tentar dar resposta à atual situação da educação mundial com suas diferenças e desafios, que nos ajudem a pensar na real capacidade dos sistemas educacionais nacionais para dar resposta às exigências de conhecimentos e destrezas necessários para competir num mundo globalizado desde uma perspectiva de qualidade da educação e equidade.

A transformação dos sistemas educativos precisa de reformas e políticas educacionais que tenham como foco melhorar e aumentar a qualidade da educação, e ao mesmo tempo gerem processos transformacionais dos sistemas educativos mediados pelas políticas públicas que procurem a equidade e a justiça social. Não é por acaso que nos focamos na inclusão como um dos elementos fundamentais deste debate, pois ela nasce da ideia de escola e sociedade que defendemos. Ao igual que todos os organismos internacionais defendem desde a Declaração de Salamanca para os contextos educativos a UNESCO (2007), dentro do Documento de discussão sobre políticas educativas no marco da II Reunião Intergovernamental do Projeto Regional de Educação para América Latina e o Caribe, afirma há anos que devemos procurar políticas que tenham como centro a transformação das instituições educativas para que sejam mais inclusivas e onde seus estudantes consigam melhores aprendizagens.

Para tanto se faz necessário, continua falando o mesmo documento, oferecer uma educação de qualidade que contenha essas propostas exige um novo modelo de escola e o desenvolvimento de políticas que facilitem sua aplicação prática. Com certeza será necessário mais recurso, porém esses não servem de muito caso não aconteçam mudanças na cultura das instituições, na organização das mesmas e nas práticas desenvolvidas. 
Neste mesmo sentido se manifestam também outros contextos, como é o caso da União Europeia que expõe a procura pela qualidade da educação de forma sistemática, e, assim afirma no informe Comissão Europeia/EACEA/Eurydice (2015, p. 3)

é certo que os sistemas de garantia da qualidade devem basear-se em princípios que vão além de uma mera abordagem de checklist: há que fomentar uma cultura empenhada na melhoria contínua da qualidade do ensino e da aprendizagem. Os Estados-Membros são encorajados a desenvolver e promover tal cultura, assegurar a transparência dos resultados da avaliação da qualidade - um processo que a Comissão Europeia se comprometeu a reforçar através da promoção da aprendizagem mútua neste domínio.

A melhoria da qualidade da educação está ligada com a formação dos gestores e docentes, dentre outros aspectos, e constitui uma preocupação central no debate político a qualquer nível, estamos convencidos que desde propostas colaborativas de compartilhar materiais e recursos muito pode ser feito, como este tipo de trabalho. A necessidade de implementar políticas e práticas direcionadas para assegurar e fomentar a qualidade da educação é um trabalho precisa da colaboração de todos.

Mas hoje em dia entendemos que não serve apenas trabalhar desde a formação inicial, sendo transcendente incorporar à discussão os avanços realizados neste campo do conhecimento e focar mais no crescimento das próprias instituições educacionais, e o trabalho de formação continuada em serviço e construção de cultura, coincidindo com o que autores, como Gairin, chamam de organizações que aprendem e que se constitui como algo singular, pois não tem duas iguais.

A situação das organizações costuma ser diferente embora nos movimentemos num mesmo contexto sociocultural. A incidência que tem no contexto, a especial forma como se relacionam seus membros, a ação diferenciada da direção, a forma como se aplica o processo organizativo, a própria história institucional e suas inquietações em relação com a melhora, configuram diferenças e as dotam de uma personalidade única e particular a cada instituição (GAIRIN, 2000, p. 34).

Quando trabalhamos sobre esta proposta de dossiê nosso foco está dentro de esta construção conceitual e ao mesmo tempo interdisciplinar e internivelar, pois só desde essa visão múltipla poderemos afrontar a realidade e propor ideias para um debate de construção coletiva, e também desde as políticas, que mude a cultura das instituições e como estas podem ser organizadas de outra forma.

Quando se fala de cultura organizacional nos estamos referindo, com Armengol (2000, p. 3) a um concepto complexo. De fato, encontramos duas correntes de pensamento cultural 
que tem influenciado neste conceito: uma se baseia no que pode ser observado diretamente sobre os membros dessa comunidade, falamos dos patrões de conduta, linguagem e utilização de objetos; a outra trabalha fundamentalmente sobre quais são os fatos que se compartilham entre os membros de uma comunidade, aqui falamos de crenças, valores e outras ideais importantes que possam compartilhar. As políticas educacionais podem e devem fazer muito neste sentido.

Começamos este dossiê com o trabalho "Educação infantil e políticas públicas no Brasil: visões e reflexões", da professora Maria Ângela Barbato Carneiro que tem como objetivo, a partir do conceito de políticas, analisar historicamente o percurso da educação infantil no Brasil e seus desafios e refletir quais as possibilidades de mudanças a serem consideradas para a próxima década.

Na sequência temos três trabalhos sobre outras tantas disciplinas diferentes "Ensino de História na Base Nacional Comum Curricular (BNCC): sentidos de diversidade nos anos iniciais", das professoras Maria Aparecida Lima dos Santos, Suzana Lopes Salgado Ribeiro e Wanessa Odorico Onório; “A gestão da sala de aula de professores de educação física na educação básica", dos professores Fábio Tadeu Reina e Willian Gabriel Felício e "A conquista da aprendizagem na matemática: assunto em construção na agenda das políticas educativas do México, para a educação média superior", da professora Cecilia Osuna Lever do México que propõe essa reflexão sobre a pesquisa ação que permite o crescimento desde dentro das instituições seja a partir das políticas ou da gestão.

O primeiro deles traz as considerações apontam que a hibridização do significante diversidade oculta, sentidos vinculados a um projeto fundamentado na perspectiva da interculturalidade funcional, que preconiza a despolitização do processo educativo pela subordinação do conhecimento em si, os conteúdos de História e a temática da diversidade, ao conhecimento para se fazer algo, discurso das competências. O segundo tem como finalidade conhecer e compreender melhor um conjunto de comportamentos do professor, habitualmente agrupados sob a designação de Gestão de Sala de Aula, dependentes de um conjunto diverso de crenças e perspectivas teóricas, sobre, entre muitos outros aspectos, o ensino, as funções e tarefas do professor. Já no terceiro deles se explica o que é una política educativa e como no México neste momento, não tem nenhum documento oficial sobre a política educativa para o futuro mais próximo e que tenha como base a reforma atual e apresenta uma breve análise que fundamenta a não consecução de sucesso acadêmico na matemática na educação média superior. O que nos serve para incrementar a qualidade da educação desde as lições aprendidas. 
Apresentamos a continuação quatro trabalhos que têm como foco a inclusão e algumas formas de práticas educativas desenvolvidas em contextos e situações diferentes. "O plano educacional individualizado e a escolarização dos alunos com deficiência intelectual: políticas e práticas”, das professoras Tânia Mara dos Santos Bassi, Vilma Miranda de Brito e Celi Corrêa Neres; “A educação das pessoas com o transtorno do espectro autista: avanços e desafios", do André Luiz Alvarenga de Souza e Alexandra Ayach Anache; "Desafios da gestão nas escolas das águas", do Washington Cesar Shoiti Nozu; Andressa Santos Rebelo e Mônica de Carvalho Magalhães Kassar e "Inclusão, educação superior e educação do/no campo: O PRONERA no contexto do capital" de Carina Elisabeth Maciel, Celia Beatriz Piatti e Gisele da Rocha Souza. Com o mesmo assunto desde quatro óticas diferentes; práticas, gestão, desafios e políticas nos é proporcionado um rico material para seguir avançando em matéria de inclusão.

O primeiro deste bloco busca apresentar e discutir a execução do Plano Educacional Individualizado (PEI), como instrumento no processo de escolarização de alunos com deficiência, na primeira etapa do Ensino Fundamental os dados coletados demonstraram que, especificamente, quanto ao professor titular/regente, existe uma fragilidade de conhecimentos sobre a educação especial e suas especificidades. Já no segundo estudo foi observado, na literatura, que há abordagens distintas usadas para ajudar na inclusão dos indivíduos com (TEA), todavia com sansão da Lei 12.764/12, esses indivíduos obtiveram uma grande vitória, porém ainda há muito que se fazer. No terceiro, referido às escolas das águas verificou-se que a autonomia necessária para a realização do trabalho de gestão encontra entraves pela insuficiência de condições materiais para um trabalho mais próximo à comunidade. E o que fecha este bloco sobre a política desenvolvida com o Programa Nacional de Educação na Reforma Agrária conclui-se que as políticas de inclusão possibilitaram o desenvolvimento do PRONERA, mas mantêm a lógica neoliberal como estruturante desse Programa que, ao ter como mentor um governo ultra neoliberal, tem seus princípios abalados pela falta de recursos e pela priorização de uma educação privatizada e meritocrática.

O dossiê apresenta na sequência seis trabalhos focados na educação superior que aborda vários e diversos aspectos que nos ajudam a refletir profundamente sobre algumas das múltiplas faces que configuram este nível educacional. "Metodologia avaliativa de conformidade com as competências de estudantes orientadas para o perfil de graduação” dos chilenos Margarita Aravena, Alejandro Berrios e Viana Ulda Figueroa; “Gestão democrática na educação superior para a diferenciação e acessibilidade curricular", dos professores André Henrique de Lima e Leonardo Santos Amâncio Cabral da UFSCar; "Desafios e perspectivas 
do estudante com deficiência visual na educação superior: análise da produção científica", assinado por José Aparecido da Costa, Rosely dos Santos Madruga, Alexandra Ayach Anache e Eladio Sebastian-Heredero; "Organização do acesso e permanência das pessoas com deficiência no Ensino Superior a partir da instauração do Programa Incluir", dos professores Patricia Tanganelli Lara e Eladio Sebastián-Heredero; "Qualidade do ensino superior: avaliação do professor universitário, uma abordagem para suas dimensões e modelos", da colombiana Lina Maria Osorio Valdes e, finaliza este bloco com o trabalho "Internacionalização como política educacional: a Universidade de Alcalá no Espaço Europeu de Educação Superior", do professor Juan-Carlos Luis-Pascual.

Inicia-se esta parte da educação superior com um trabalho que aprofunda na avaliação para a obtenção de perfis que faz parte do gerenciamento constante das instituições de nível superior, que deve ser constantemente socializado e comunicado na estrutura orgânica da instituição, assim a realização de avaliações das competências dos alunos implica a criação de marcos avaliativos, que devem ser constantemente orientados, acompanhados e supervisionados. Continua com um estudo sobre a Gestão Democrática na Educação Superior, pois para além da gestão de recursos humanos, financeiros, tecnológicos e materiais, prevê a inter-relação da gestão pedagógica, do acesso ao currículo, da ação docente, dos resultados, dos espaços, das condutas e interações culturais, os resultados indicaram que, iniciativas para (des)construção sobre concepções de deficiência e de formação profissional, suscitaram a comunidade acadêmica a identificar e a questionar sobre diversas barreiras presentes no contexto acadêmico, baseando o planejamento de ações que fomentassem mudanças positivas nesse cenário.

A inclusão do estudante com deficiência visual na educação superior ainda tem sido desafiadora para os gestores e professores para garantir êxito acadêmico, é a apresentação do seguinte trabalho que nos traz duas conclusões importantes uma que o número de estudantes com deficiência visual na Educação Superior tem aumentado mais de 50\%, que existe um conjunto de legislação que favorece a inclusão, porém não aparecem ainda as condições, seja de recursos/tecnologias ou de formação de professores para sua efetivação, conforme as pesquisas e que o atendimento educacional especializado, garantido por lei, ainda não se percebe materializado. Na sequência e com foco no mesmo assunto se aborda o Programa Incluir que influenciou as políticas institucionais, para a implementação de ações de acessibilidade para pessoas com deficiência no ensino superior, em todos os estados brasileiros, os resultados desse período investigado revelaram o avanço da implementação das políticas públicas, após 2005, com a criação dos núcleos de acessibilidade e os apoios para a inclusão de 
jovens e adultos com deficiência, contudo foi possível identificar a necessidade da formação docente e dos profissionais que atuam nestas instituições para eliminar as barreiras atitudinais e comunicacionais localizadas em muitas instituições de ensino superior.

Ainda se apresenta um trabalho sobre a avaliação do professor universitário como uma questão em que há atenção crescente, dada a sua relação com os resultados da aprendizagem dos alunos e a qualidade dos programas e universidades, na atualidade existem tantos modelos de avaliação docente como sistemas educativos e universidades, justamente pela dificuldade de chegar a acordos frente no que significa ser um bom docente, o que também está diretamente vinculado com os contextos, as expectativas e a visão, missão e prioridades da instituição educacional ou a comunidade que realiza a avaliação.

Por fim, acaba este dossiê com uma análise sobre um tema muito importante hoje em dia nas agendas políticas brasileiras a internacionalização e as novas funções da universidade no desenvolvimento integral do aluno, pois supõem uma estratégia de inovação contínua para adequar e até antecipar as necessidades prospectivas, tanto profissionais quanto pessoais, dos cidadãos que coexistirão em uma realidade global, interdependente e mutável, para tanto a política educacional precisa ter um objetivo claro que permita combinar o desenvolvimento das competências de ensino dos professores com uma perspectiva baseada na aprendizagem dialógica, avaliação formativa e compartilhada, trabalho colaborativo, inclusão e gerenciamento da incerteza.

Mas hoje em dia outro elemento entrou em jogo: a pandemia de 2020 com o Covid-19 e todas as mudanças e questionamentos sobre que está sendo feito e o que virá que mantém a mais de 1,5 bilhões de estudantes sofrendo o impacto do fechamento das escolas e universidades e para tanto a Coalizão Global de Educação lançada pela UNESCO (2000) promulgou um documento que procura facilitar as oportunidades de aprendizagem inclusiva para crianças e jovens durante este período de interrupção educacional súbita e sem precedentes e minimizar o impacto frente as classes mais desfavorecidas da sociedade.

Em tempo estimula aos governos e instituições para um esforço extraordinário em investimentos para garantir a aprendizagem a distância ou remota que, de alguma forma, mitigue a interrupção das aulas presenciais, causada pela Covid-19, e estabelecer abordagens criativas e colaborativas para desenvolver sistemas educacionais abertos e flexíveis e uma reflexão para a nova realidade das escolas e universidades.

Esperamos e desejamos que este dossiê possa nos ajudar na caminhada de inovação constante na educação, na construção de instituições educativas inclusivas e de qualidade que aprendam a partir das fortalezas internas das mesmas desde uma perspectiva colaborativa e 
gestores educacionais reflexivos e críticos que não poupem esforços seja nos investimentos quanto na dinamização de políticas para a formação de cidadãos mais comprometidos com uma sociedade mais justa e equitativa.

\section{REFERÊNCIAS}

ARMENGOL, C. La cultura colaborativa: primer paso para la consecución de instituciones educativas de calidad. In: MARTÍN, M. (coord.). La calidad de los centros educativos. Universidad Alcalá, 2000.

COMISSÃO EUROPEIA/EACEA/Eurydice. Garantia da Qualidade na Educação:

Políticas e Abordagens à Avaliação das Escolas na Europa. Relatório Eurydice. Luxemburgo: Serviço de Publicações da União Europeia, 2015.

FRAILE, A. El sistema universitario europeo como modelo posible para la educación superior latinoamericana. Revista Electrónica de Investigación Educativa, México, v. 8, n. 1, p. 1$15,2006$.

GAIRÍN, J. Cambio de cultura y organizaciones que aprenden. Educar 27, n. 27, p. 31-85, 2000.

UNESCO. Educación de calidad para todos, un asunto de derechos humanos. Documento de discusión sobre políticas educativas en el marco de la II Reunión Intergubernamental del Proyecto Regional de Educación para América Latina y el Caribe (EPT/PRELAC) 29 y 30 de marzo de 2007. Buenos Aires: UNESCO. 2007

UNESCO. Global education coalition. 2020. https://en.unesco.org/news/unesco-ralliesinternational-organizations-civil-society-and-private-sector-partners-broad Consultado em 17 ago. 2020

\section{Como referenciar este artigo}

ANACHE, A. A.; SEBASTIÁN-HEREDERO, E. Qualidade e equidade na educação: uma visão desde as políticas e a gestão educacional. Revista on line de Política e Gestão Educacional, Araraquara, v. 24, n. esp. 2, p. 938-945, set. 2020. e-ISSN:1519-9029. DOI: https://doi.org/10.22633/rpge.v24iesp2.14341

Submetido em: $30 / 04 / 2020$

Revisões requeridas em: 26/06/2020

Aprovado em: 30/07/2020

Publicado em: 30/09/2020 